The copy is the pre-print version of the accepted manuscript by SIMS 2016.

The Published version is available on IEEE Xplore: http://ieeexplore.ieee.org/document/7802907/

\title{
Developing A Toolbox of Supports for Small and Medium Sized Manufacturing Companies
}

John Moore, Anne Loughran and Edel McCusker (South West College, UK), Wei Deng Solvang, Gabor Szeibig and Hao Yu (Arctic University of Norway), Asa Ericson, Johann Holmqvist and Johann Wenngren (Lulea University of Technology, Sweden), Sakari Pieska, Juoni Vahasoyrinki and Heidi Kaartinen (Centria University of Applied Sciences, Finland).

\begin{abstract}
TARGET is a collaborative project involving a partnership of universities and institutes of higher education in UK, Ireland, Norway, Finland and Sweden. The project will develop tools to enhance capacity in regional manufacturing companies to adapt and embrace new technologies and innovation. This is to be done in collaboration with small/medium sized manufacturing engineering companies - developing, applying and piloting the tools through individual companies' processes. The Toolbox developed will consist of subsets such as Digital manufacturing (robotics and simulation), New Ideas and Thinking (human centred and environmental thinking, competitiveness), Business Models and modern Product Innovation. On completion of the Project, the Toolbox of supports will be made available for use through open access to manufacturing companies. The initial project phase with development of a Toolbox suitable for use in all the project partners' regions is presented.
\end{abstract}

\section{Introduction}

Manufacturing companies in Europe's northern periphery region are predominately small in size and face considerable challenges like geographical isolation from major markets and a lack of the benefits offered by more populous and urbanised economic clusters. With challenging climate conditions, sparseness of population and remoteness from centres of industry, commerce, services, transport hubs and markets. When combined with global trends that see a shift in manufacturing to lower cost and developing economies with rapid advances in new technologies this means that support measures are needed to strengthen the manufacturing sector in this region. To remain competitive in the global market manufacturing companies must adopt new technologies, this is driven by both the customer and also available technological advances, Lasi et al, 2014.

However, manufacturing in the region has many important strengths, including regional and niche specific competencies that are world leading in sectors that are unique to the region. For example; technologies, processes and products dealing with timber and technologies for cold conditions and wireless communications in Scandinavia; extractive industries and materials handling in Ireland, and construction and building technologies and renewable energy and energy efficient applications throughout.

The manufacturing base currently contributes significantly to the economy of thru region and provides substantial employment. Given the right support there is potential for considerable growth. The Companies involved mostly fall into the category classified by the EU as Small and Medium sized Enterprises (SME's); the definition of which is "an enterprise which employs fewer than 250 persons and which has an annual turnover not exceeding 50 million euro, and/or an annual balance sheet total not exceeding 43 million euro."

The TARGET Project is a three year collaborative programme funded by the Interreg IVA Northern Periphery and Arctic (NPA) Programme. It involves the following regional technical universities and higher education institutes;

- Narvik University College, Norway

- Centria University of Applied Sciences, Finland

- Luleå University of Technology, Sweden 
The copy is the pre-print version of the accepted manuscript by SIMS 2016.

The Published version is available on IEEE Xplore: http://ieeexplore.ieee.org/document/7802907/

- Cavan Innovation and Technology Centre

- South West College, Northern Ireland (UK)

\section{The Toolbox Methodology}

The overall aim of the TARGET Project is to develop, implement and refine a suite of innovation supports for manufacturing Small and Medium sized Enterprises (SME's) in the NPA Region with the aim of giving them new skills, expertise, tools and concepts to allow them to increase their global competitiveness and to be innovative leaders in their sectors.

This will be achieved by developing and road testing a Toolkit which will help support and equip manufacturing companies with a new skill set, knowledge and capabilities, making them better equipped to be innovative in their process and developing new and novel ways of manufacturing their product or service; This Toolbox is being developed with the goal of delivering a clear pathway for manufacturing to achieve process automation by embracing Industry 4.0 and reap the benefits reported by others. Manufacturing businesses that are investing in automation report that they are seeing clear benefits, Rigby (2015). Analysis of Industry 4.0's impact on German manufacturing found that the growth it stimulates leads to a $6 \%$ ingress in employment during the next 10 years, as reported by the Economist Intelligence Unit, in 2016. It is hoped that adding diversification and versatility to manufacturing companies, will help safeguard employment and improve the quality and sustainability of jobs and the entrepreneurial nature of the SME's. "Industries and countries will embrace Industry 4.0 at different rates and in different ways", Russmann et al, (2015). By developing this Toolbox with manufacturing companies - and through its later adoption by other companies, knowledge of new available technologies will be disseminated so aiding in new product development and product improvement. Transnational contacts will encourage companies to create links with like-minded people and this will increase the access of manufacturing firms to the innovation environment - which is often inaccessible to peer companies in remote and peripheral regions.

\section{Survey of Manufacturing Companies and Engagement}

An initial Survey of manufacturing SMEs in each project partner's area was carried out, where Companies were asked about specific issues relating to their business and future prospects under the headings of; strategic issues, market trends, barriers to growth and opportunities. The following core themes, common to all areas, were identified:

Strategic issues: $\quad$ Staff recruitment and obtaining staff with the necessary skills Streamlining and Lean Manufacture

Market trends: Increasing focus on the environment, energy efficiency and waste management

Markets and business growing

Need for increased innovation

Barriers to growth: Lack of skills in workforce

Lack of competitiveness

Currency fluctuations

Opportunities: Exports

Innovation

Following this, a total of 30 companies were selected to engage with the Project, approximately five in each area; to develop and pilot a diagnostic Toolbox for identifying the best "Tools" for a company's needs and to apply this Toolbox to support the company's development. To ensure open and inclusive selection of appropriate Companies to the Project, a selection methodology was employed as follows;

1. Open advertisement for manufacturing companies to engage with the Project. 
The copy is the pre-print version of the accepted manuscript by SIMS 2016.

The Published version is available on IEEE Xplore: http://ieeexplore.ieee.org/document/7802907/

2. Selected companies to meet pre-set eligibility, suitability and selection criteria for participation, as agreed between project partners and clearly communicated to applicant companies prior to selection. Applicant companies will be scored against these criteria.

3. Company selection on the basis of ranking applicant companies in order of scores against the selection criteria.

The following scoring matrix was adopted for the purpose of ranking applicant Companies;

- Scale and depth of activity in research, implementation of new techniques or methodologies $25 \%$

- Capacity, knowledge and expertise of staff that will engage with the project $-20 \%$

- Demonstrated importance of introduction of new products, techniques and tools to the company $-20 \%$

- Demonstrated importance of introduction of new products, techniques and tools to the particular manufacturing sector the company is in - $10 \%$

- Ability to commit time and resources to the project to ensure its successful completion - $10 \%$

- Current level of technological knowledge and deployment within the company and how advanced it is in terms of industry leaders $-15 \%$

On completion of the project the completed Toolbox will be available as Open Source for any Company to access - free of charge.

\section{Development of the Toolbox}

Existing intervention methodologies have been developed individually by the project partners and have been shared with the other partners for implementation in their area with participating manufacturing companies.

The following Toolbox modules are under development by the project.

1. Innovation - Development of product innovation cycles, product development and application of new approaches, the product process and design map.

2. Digital Manufacturing - to enable users collaborate digitally in different phases of the product lifecycle from idea generation in design to manufacturing and maintenance.

3. Business Models - Application of peripheral thinking, creativity solutions and testing of new market and business model approaches to the manufacturing sector in order to enhance product development cycles, increase competitiveness, develop new markets and reduce time to markets.

4. Productivity - Introducing a combination of Innovation, Digital Manufacturing and Business Models into the production cycle will lead to more effective and efficient manufacturing process.

TARGET-toolbox

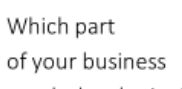

needs developing?

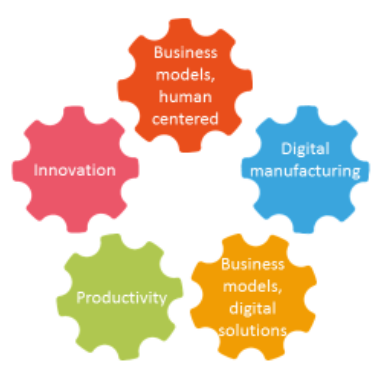

Figure 1: TARGET Project Toolbox Themes 
Each partner adopted one theme from Figure 1 to develop which is best suited to their expertise and the needs of their region. To illustrate this approach the development of the New Ideas and Thinking (Ireland) module is described.

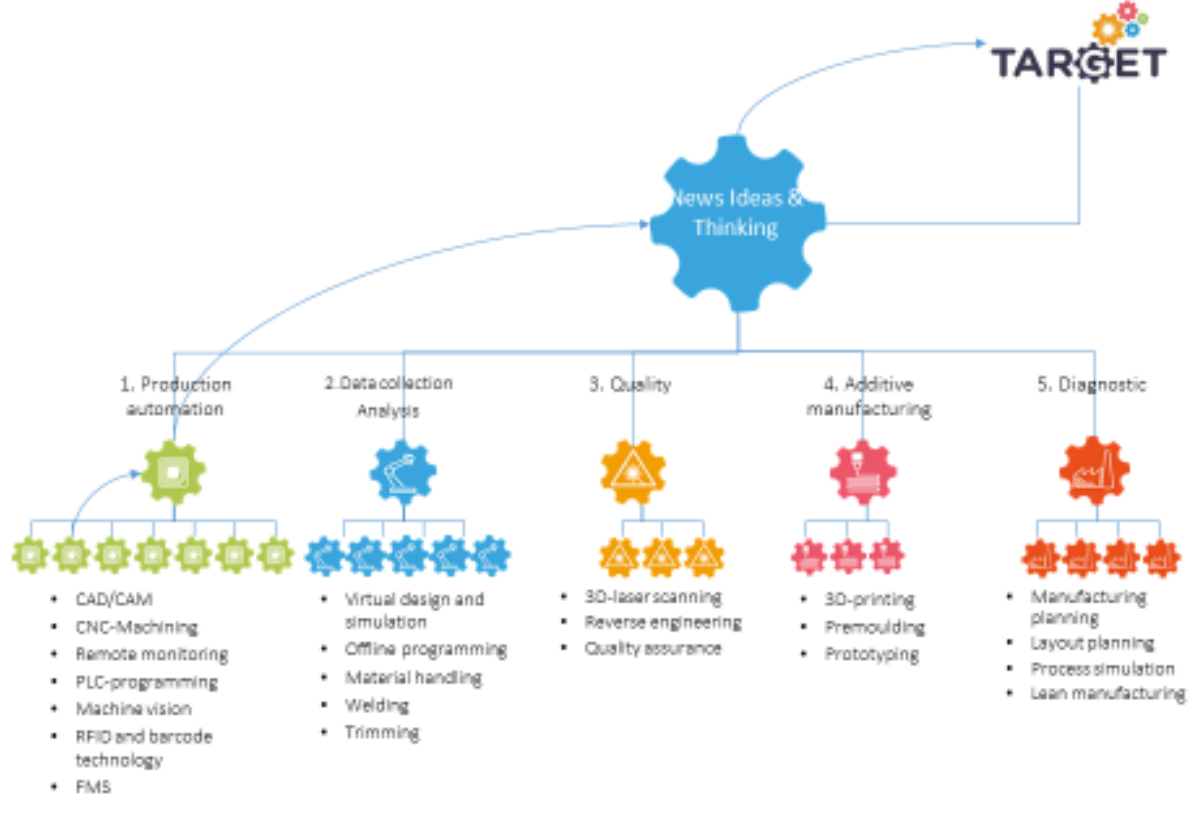

\section{Figure 2: Toolbox Model adopted for New Ideas and Thinking (Ireland)}

This model (Figure 2) was developed to provide Companies with a platform to facilitate change in their own manufacturing processes and was tested with three Companies on identified developmental challenges. Following this the algorithim shown in Figure 3 was developed specifically to help Companies identify and scope developmental projects. It is currently being tested by a number of companies.

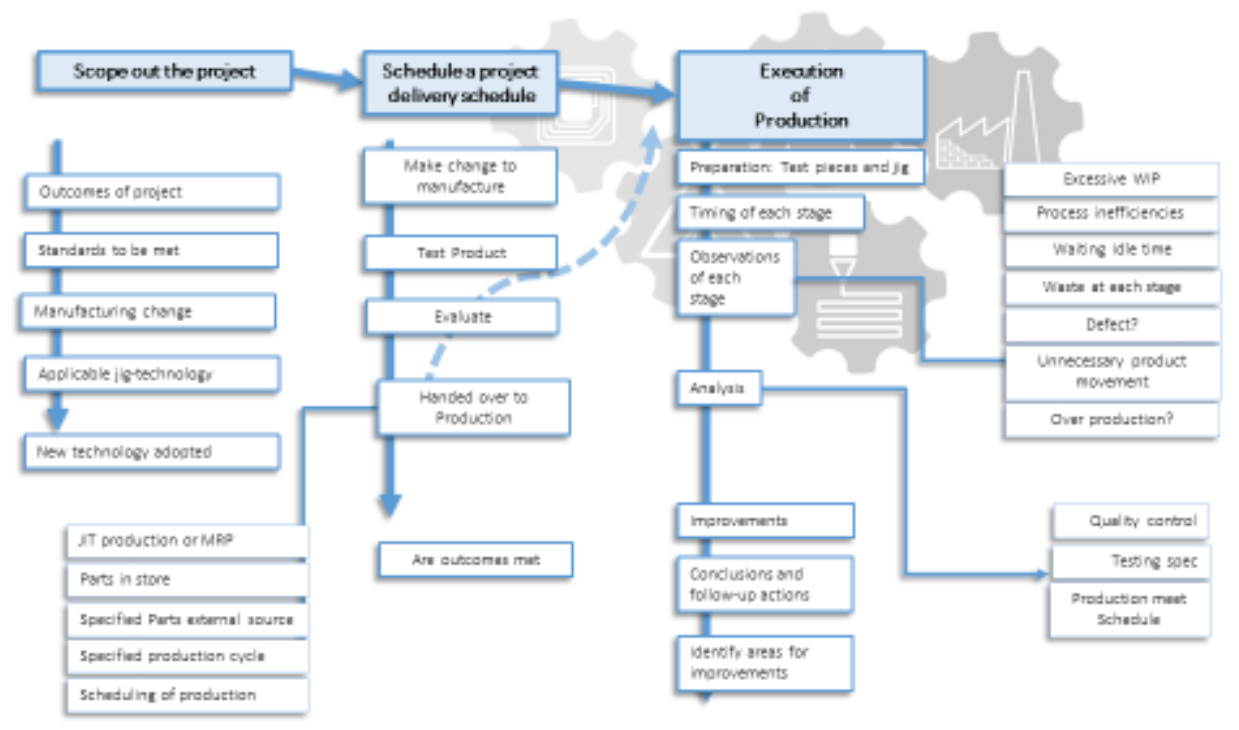

Figure 3 Algorithim for the problem solving kit (Ireland) 
In developing the themes for the Toolbox illustrated in Figure 2; five tools or methods emerged;

- Production Automation

- Data Collection and Analysis

- Quality

- Additive Manufacturing

- Diagnosics

Each of the Project Partners have worked on their own Toolbox; although each has been generated from different areas, there is an emerging overlap of tools and methods. A mapping exercise of each of these is illustrated in Figures 4 to 7.

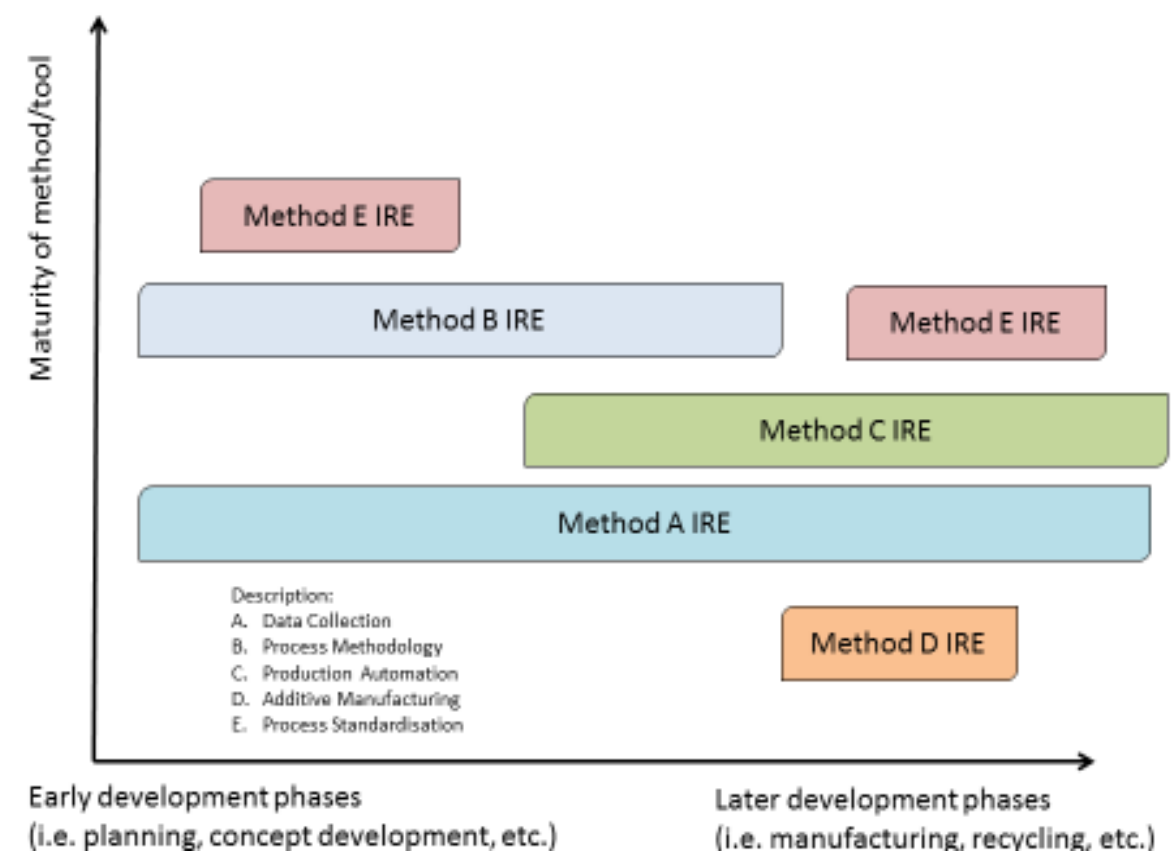

Figure 4: Comparison of methods or tools with the production cycle (Ireland)

There is a mature approach to Diagnostic tools in Ireland in the early and late stages of the production cycle. Automation is developing in the manufacturing and recycling stages but is not introduced into the planning stages. However the process methodology is well established in the earlier stages such as process design and costing. Companies in Ireland are beginning to see the importance of data collection all the way through the production cycle and this is beginning to develop throughout. 


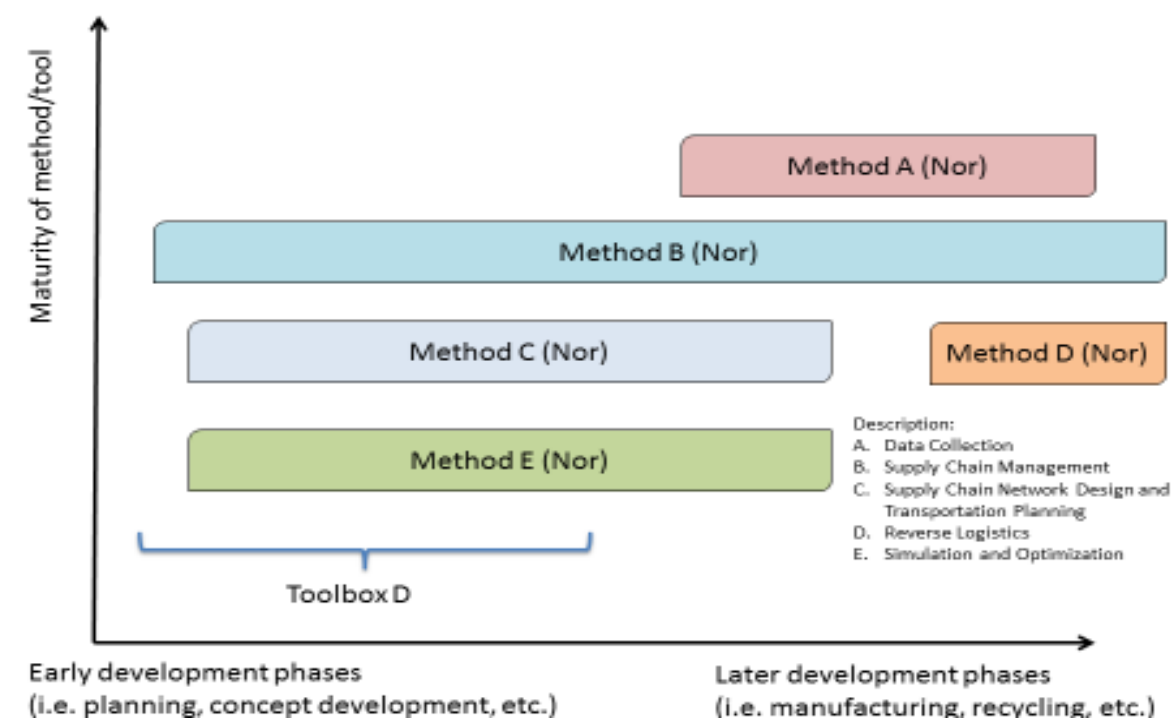

Figure 5: Comparison of methods or tools with the production cycle (Norway)

Fig 5 (Norway) shows a mature approach to data collection in the later stage of the process cycle with well-established supply chain management throughout all stages of the production cycle. The Supply Chain Network Design and Reverse logistics are in their growth stage with a lower level of maturity for both supply chain network and also design and simulation and optimisation.

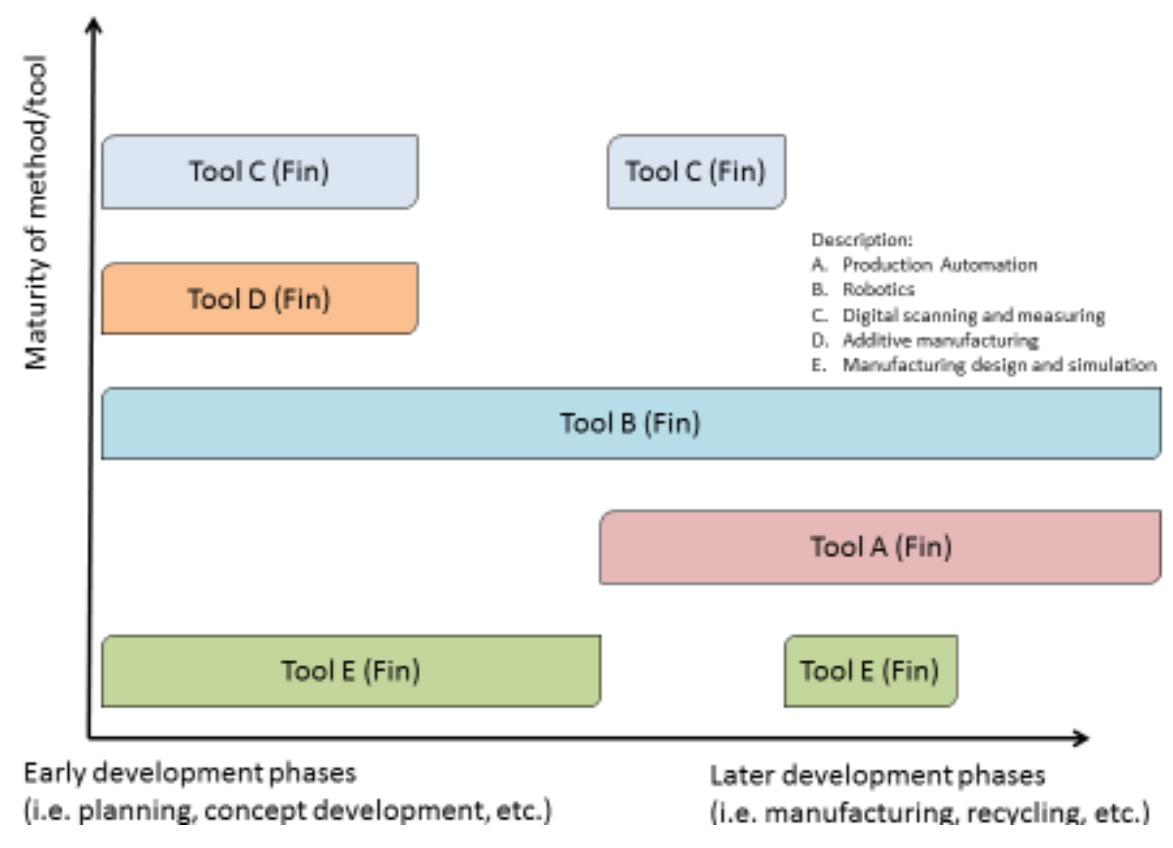

Figure 6: Comparison of methods or tools with the production cycle (Finland)

Fig 6 (Finland) shows that Digital Scanning and Measuring have reached maturity in both the early and mid-stages of the production cycle. There is evidence of growing use of Additive Manufacturing in the early planning, conceptual development stage with a growing use of Robotics throughout the production cycle of a product. Production Automation is growing in the later stages for the manufacturing, recycling and dispatching of the product. Manufacturing Design and Simulation are in early infancy in both the early planning and conceptual development stages and also in the later phases; for example the manufacturing stage. 


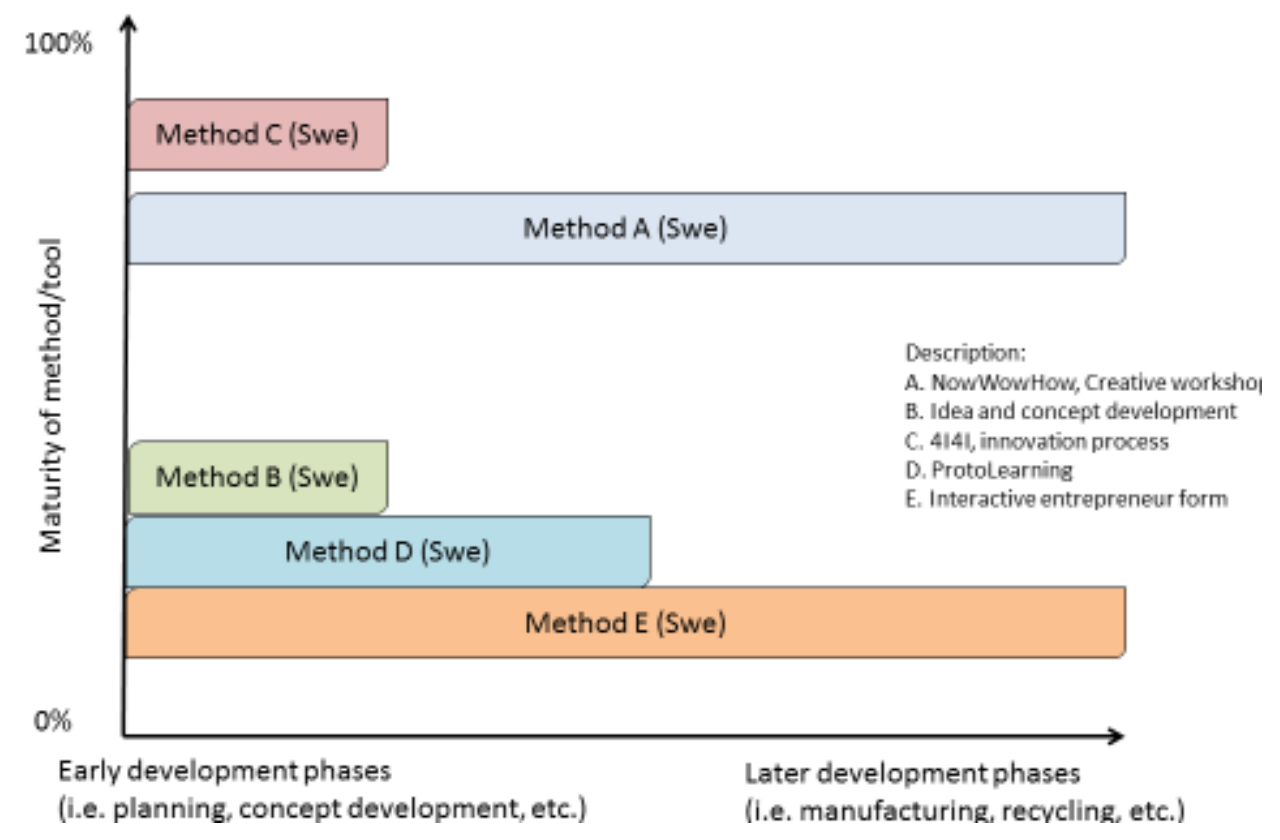

Figure 7: Comparison of methods or tools with the production cycle (Sweden)

Fig 7 (Sweden) shows a Toolbox of conceptual ideas demonstrating a high level of maturity for the creative process in all areas of the production cycle. Established methodologies are employed throughout - the NOW WOW HOW Creative Workshop, 4I4I Innovation Process, ProtoLearning and Interactive Entrepreneur Form. These should be transferable to the other Project participants. The Interactive Entrepreneur Form is in early infancy but it is beginning to develop in all areas of the production cycle. The 4I4I Innovation Process is well established in the early stages with Protolearning and the application of Idea and Concept Development in early infancy.

\section{Conclusion}

At this early stage of development it has transpired that there are similarities with each of the Project Partners' developing Toolboxes, which are beginning to converge into one single Toolkit as intended. 
The copy is the pre-print version of the accepted manuscript by SIMS 2016.

The Published version is available on IEEE Xplore: http://ieeexplore.ieee.org/document/7802907/

\section{References}

Baur, C, \& Wee,D. Manufacturings Next Act McKinsey and Company.

Accessed from http://www.mckinsey.com, Jun 2015

Bergstrom, M., Torlind, P. and Ericson, A. 4I4I - Four I:s For Innovation. Luleå University of Technology, 2010

Ericson, A. and Torlind, P. A Deep Dive into Creative Thinking: The Now Wow How Framework. In: Proceedings of the $19^{\text {th }}$ International Conference on Engineering Design, Seoul, Korea, Vol 7, 337-346, 2013.

The Economist Intelligence Unit. Cisco Technology Radar.

Accessed from htps://techradar.cisco.com, Jan 2016

Lasi, H., Fettke, P., Kemper, H., Feld, T., \& Hoffmann, M. Industry 4.0. Business \& Information Systems Engineering, 6(4), 239-242, 2014

Rigby, M.. Future Proofing UK Manufacturing: Current investment trends and future opportunities in robotic automation. Barclays/Development Economics

Accessed from http://barclayscorporate.com, 2015

Russmann, M. Lorenz, M. Gerbert, P. Waldner, M. Justus, J. Engel, P. \& Harnisch, M. Industry 4.0, The Future of Productivity and Growth in Manufacturing Industries, The Boston Consulting Group, Nov 2015

Accessed from http://www.inovasyon.org/pdf/bcg.perspectives_Industry.4.0_2015.pdf

\section{Acknowledgements}

The TARGET Project is supported by the European Union Northern Peripheries and Arctic (NPA) Programme under Priority 1: Innovation, Research and Technology Development.

The NPA Programme has been established to help peripheral and remote communities on the northern margins of Europe to develop their economic, social and environmental potential. 